Research Article

\title{
Evolution of satellite DNA sequences in two tribes of Bovidae: A cautionary tale
}

\author{
Mariella Nieddu ${ }^{1}$, Roberto Mezzanotte ${ }^{1}$, Giuseppina Pichiri ${ }^{2}$, Pier Paolo Coni ${ }^{2}$, Gian Luca Dedola ${ }^{3}$, \\ Maria Luisa Dettori ${ }^{3}$, Michele Pazzola ${ }^{3}$, Giuseppe Massimo Vacca ${ }^{3}$ and Renato Robledo ${ }^{1}$ \\ ${ }^{1}$ Department of Biomedical Sciences, University of Cagliari, Monserrato, Italy. \\ ${ }^{2}$ Department of Surgical Sciences, University of Cagliari, Cagliari, Italy. \\ ${ }^{3}$ Department of Veterinary Medicine, University of Sassari, Sassari, Italy.
}

\begin{abstract}
Two clones, Bt1 from Bos taurus and Om1 from Ovis orientalis musimon, were used as probes for hybridization on genomic DNA and on metaphase chromosomes in members of Bovini and Caprini tribes. Bt1 and Om1 are sequences respectively belonging to the 1.715 and 1.714 DNA satellite I families. Southern blots and fluorescence in situ hybridization experiments showed completely coherent results: the Bovini probe Bt1 hybridized only to members of the Bovini tribe and not to members of Caprini. Likewise, the Caprini probe Om1 hybridized only to members of the Caprini tribe and not to members of Bovini. Hybridization signals were detected in the heterochromatic regions of every acrocentric autosome, except for two pairs of autosomes from Capra hircus that did not show hybridization to probe Om1. No signal was detected on $\mathrm{X}$ and $\mathrm{Y}$ chromosomes or on bi-armed autosomes. Remarkably, probe Om1 showed almost 100\% homology with a bacterial sequence reported in Helicobacter pylori.
\end{abstract}

Keywords: Bovidae, satellite DNA, fluorescence in situ hybridization, pericentromeric region.

Received: April 9, 2015; Accepted:July 17, 2015.

\section{Introduction}

The Bovidae, an important mammal family in the Artiodactyla order, includes a number of species such as cattle, sheep and goat, which are highly relevant from both economic and social viewpoints. Moreover, Bovidae is the most diverse family within the Artiodactyla order, and includes approximately 140 extant species (Nowak, 1999) that have been classified in several subfamilies, which, in turn, are further divided into tribes (Gentry, 1992; Gallagher Jr et al., 1999). However, the systematic and phylogenetic relationships among the various species are still under discussion.

Many studies have attempted to reconstruct phylogenesis in Artiodactyla by means of the analysis of endogenous retroviruses (Chessa et al., 2009), microsatellites (Vacca et al., 2011), gene sequences (Carcangiu et al., 2011) and mitochondrial DNA (Naderi et al., 2007; Achilli et al., 2009; Vacca et al., 2010; Lei et al., 2011; Meadows et al., 2011). Nevertheless, the systematic of the Bovidae remains controversial, because evolutionary steps such as rapid radiation and morphological convergence led to a

Send correspondence to Renato Robledo. Department of Biomedical Sciences, University of Cagliari, Cittadella Univesitaria, 09042 Monserrato, Italy. E-mail: rrobledo@unica.it. highly variable chromosome number within this family, ranging from 30 to 60 (Chaves et al., 2005). Domestic cattle is considered to have the ancestral karyotype $(2 n=60)$ due to the presence of telocentric chromosomes. However, rearrangements such as centric fusions between uniarmed chromosomes led to karyotype differences, e.g. the river buffalo (B. bubalis bubalis) with $2 \mathrm{n}=50$ and the swamp buffalo ( $B$. bubalis kerebau), with $2 \mathrm{n}=48$ (Iannuzzi et al., 1996).

A significant portion of eukaryotic genomes is represented by repeated sequences, among which a large fraction includes sequences repeated in tandem, known as satellite DNAs (for a review, see Plohl et al., 2008), often located at or near the centromeres (D’Aiuto et al., 1997). A typical satellite DNA is composed of thousands of monomeric units, arrayed in tandem in head-to-tail configuration and located in constitutive heterochromatin (Plohl et al., 2008). Since no protein-coding function has been assigned to satellite DNAs to date, these sequences are not evolutionarily constrained, and therefore change more rapidly (Pita et al., 2009) than any other genomic sequences, making them useful for comparative studies. In this paper, we analyzed two satellite sequences, one obtained from Bos taurus and the other from Ovis orientalis musimon, in four members of the Bovinae and Caprinae subfamilies, respectively Bos taurus, Bubalus bubalis, Ovis orientalis musimon and 
Capra hircus. Our results provide support to the idea that the distribution and organization of DNA satellite sequences may provide an additional tool to help in resolving the still-controversial points involved in the systematics of Bovids.

\section{Material and Methods}

\section{DNA samples and probes}

Sampling included the following species: Bos taurus, Bubalus bubalis, Ovis orientalis musimon and Capra hircus. Peripheral blood samples were collected and DNA was extracted according to Cau et al. (1992). Genomic DNA from Bos taurus was digested to completion with restriction enzyme HaeIII. Following gel electrophoresis, a discrete band of approximately 300 base pairs was isolated, purified and cloned in vector pJET1.2/blunt (Thermo Scientific). Likewise, DNA from Ovis orientalis musimon was digested with $A l u \mathrm{I}$, and a discrete band of approximately 800 base pairs was isolated, purified and cloned in the same vector. Several clones were sequenced (Macrogen Europe, Amsterdam); two of them, Bt1 (from Bos taurus digested with HaeIII) and Om1 (from Ovis orientalis musimon digested with $A l u \mathrm{I}$ ), were used as probes for Southern and in situ hybridization.

\section{Chromosome preparation}

Metaphase preparations were obtained following the procedures described in Moorhead et al. (1960). Briefly, heparinized lymphocytes were cultured for $72 \mathrm{~h}$ at $37^{\circ} \mathrm{C}$ in RPMI-1640 medium (Invitrogen), supplemented with 10\% fetal bovine serum (FBS), 1\% penicillin and streptomycin, and $100 \mu \mathrm{L} / \mathrm{mL}$ phytohemoagglutinin (PHA). Cells were arrested at metaphase by adding colcemid $(10 \mathrm{mg} / \mathrm{mL})$ for 2 h. Hypotonic treatment was carried out with $0.075 \mathrm{M} \mathrm{KCl}$ for $10 \mathrm{~min}$; cells were then fixed with 3:1 methanol:acetic acid for $30 \mathrm{~min}$ and spread onto clean slides.

\section{Fluorescence in situ hybridization}

Slides containing chromosomes were treated with $70 \%$ formamide (in $2 \mathrm{xSSC}$ ), $\mathrm{pH} 7$, at $70{ }^{\circ} \mathrm{C}$ for $2 \mathrm{~min}$ and then dehydrated in an increasing ethanol series. Bt1 probe from Bos taurus DNA and Om1 probe from Ovis orientalis musimon DNA were labelled with Spectrum Green dNTP (Vysis) by nick translation (Nick Translation System BRL) and, after precipitation, they were dissolved in hybridization buffer $(50 \%$ formamide, $10 \%$ dextran sulfate, $2 \mathrm{xSSC}, \mathrm{pH} 7$ ) to a final concentration of $20 \mathrm{ng} / \mu \mathrm{L}$. Probes were then denatured at $70{ }^{\circ} \mathrm{C}$ for $10 \mathrm{~min}$, put on ice for 5 min and hybridized overnight at $37^{\circ} \mathrm{C}$ in a wet chamber. Following hybridization, slides were washed once in $2 \mathrm{xSSC}$ in $50 \%$ formamide for $5 \mathrm{~min}$ and twice in $2 \mathrm{xSSC}$ for $3 \mathrm{~min}$. Slides were finally counterstained with $1 \mu \mathrm{g} / \mathrm{mL}$ propidium iodide (Sigma Aldrich). Results were evaluated with a digital image analysis system consisting of an epifluorescence Nikon Optiphot microscope and chargecoupled device camera (COHU) interfaced to the CytoVision system, version 2.7 (Applied Imaging).

\section{Results}

\section{Sequencing and Southern blotting}

Probe Bt1, isolated from Bos taurus, was 344 base pairs long (GenBank accession number: KM272302). The sequence, analyzed with BLAST (Altschul et al., 1997), showed very high homology (ranging from $99 \%$ to $93 \%$ ) with several bovine satellite DNA sequences belonging to the 1.715 satellite I family. Likewise, homology of $94 \%$ and $83 \%$ was detected with DNA satellite I sequences of Bison bonasus and Bubalus bubalis, respectively. Accordingly, in Southern blot experiments, probe Bt1 gave strong positive signals when hybridized to Bos taurus and Bubalus bubalis genomic DNA, whereas no bands were detected when the probe was hybridized to Ovis orientalis musimon or to Capra hircus genomic DNA (Figure 1).

Probe Om1, isolated from Ovis orientalis musimon, was 816 base pairs long (GenBank accession number: KM272303). BLAST analysis showed that the sequence is nearly identical to satellite DNA sequences belonging to the 1.714 satellite I family present in Ovis aries and Ovis amon, and has high homology (87\%) with a similar satellite DNA sequence present in Capra hircus. When hybridized to genomic DNAs, the Om1 probe gave positive signals in Ovis orientalis musimon and Capra hircus, whereas no signal was detected when the probe was tested with Bos taurus and Bubalus bubalis genomic DNA (Figure 2). Surprisingly, BLAST analysis showed that probe Om1 has a very

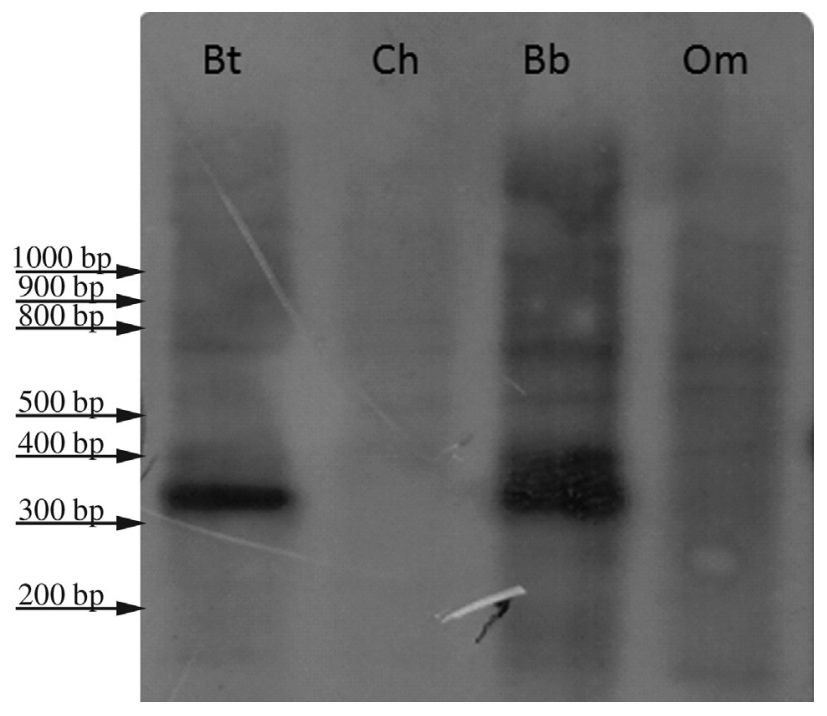

Figure 1 - Bos taurus genomic DNA digested with HaeIII and hybridized to probe Bt1. Signals are detected in genera Bos and Bison, but not in genera Ovis and Capra $. \mathrm{Bt}=$ Bos taurus, $\mathrm{Ch}=$ Capra hircus, $\mathrm{Bb}=$ Bubalus bubalis, $\mathrm{Om}=$ Ovis orientalis musimon. 


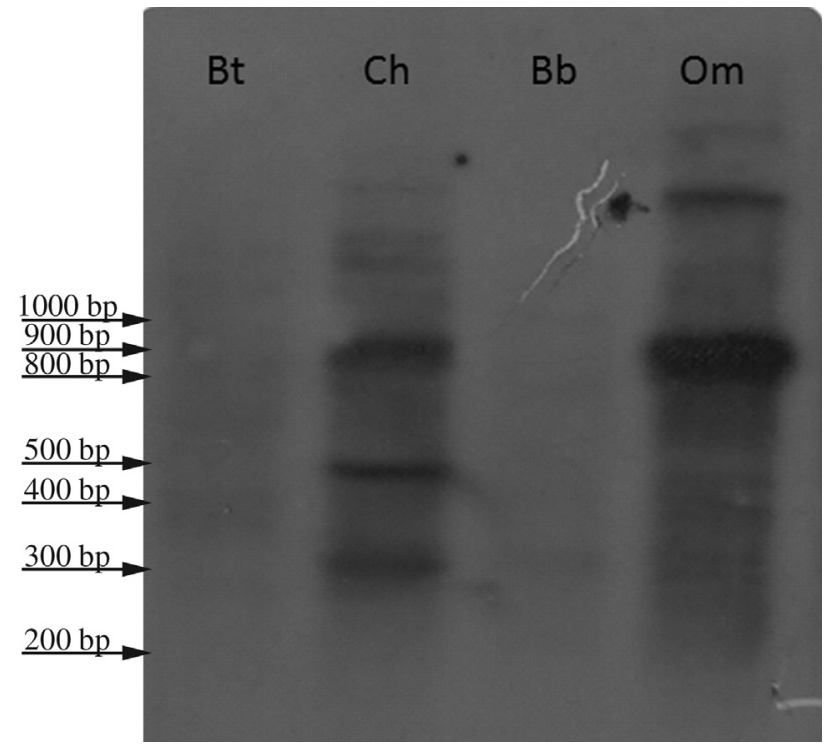

Figure 2 - Ovis orientalis musimon genomic DNA digested with AluI and hybridized to probe Om1. Signals are detected in genera Ovis and Capra, but not in genera Bos and Bison. Abbreviations as in Figure 1.

high degree of homology, i.e. almost $100 \%$, with a bacterial sequence reported in Helicobacter pylori.

\section{Fluorescence in situ hybridization}

The same probes were used for in situ hybridization on metaphase chromosomes. The Bt1 probe gave a positive signal on all pericentromeric regions of the acrocentric autosomes of Bos taurus, while no signal was detected on the $\mathrm{X}$ or the $\mathrm{Y}$ chromosome (Figure 3A). The same probe gave a positive signal on pericentromeric regions of all acrocentric autosomes of Bubalus bubalis, whereas no signal was observed in the ten bi-armed chromosomes or on the $\mathrm{X}$ and $\mathrm{Y}$ chromosomes (Figure 3B). No signal was detected on any chromosome of Ovis orientalis musimon and Capra hircus (data not shown).

The Om1 probe gave a positive signal on pericentromeric regions of all acrocentric chromosomes of Ovis orientalis musimon, but we detected no signal on bi-armed autosomes or on the $\mathrm{X}$ and $\mathrm{Y}$ chromosomes (Figure 3C). Exactly the same pattern was detected in chromosomes of Ovis aries (data not shown). In Capra hircus, a slightly different pattern was observed, with two additional pairs of autosomes giving no signal (Figure 3D). Finally, the Om1 probe did not hybridize on Bos taurus or Bubalus bubalis chromosomes (data not shown).

\section{Discussion}

We analyzed two DNA satellite I sequences in different species belonging to the Bovidae family. The two sequences, Bt1 and Om1, were nearly identical to previously-described sequences reported as belonging respectively to the 1.715 and 1.714 DNA satellite I families
(Chaves et al., 2005). When used as probes in Southern blots or in FISH, Bt1 and Om1 showed completely coherent results. Indeed, the Bt1 sequence hybridized to Bos taurus and Bubalus bubalis chromosomes and genomic DNA, while no signal was detected in Capra hircus and Ovis orientalis musimon. Accordingly, the Om1 sequence hybridized only to Capra hircus and Ovis orientalis musimon chromosomes and genomic DNA, but not to Bos taurus and Bubalus bubalis.

Similar sequences were analyzed in previous studies, though with conflicting results: Chaves et al. (2005) found that probe pBtKB5, from cattle, which shows 97\% identity with probe Bt1, showed a positive signal in FISH experiments carried out on Caprini (genera Ovis and Capra). Other authors (Kopecna et al., 2012) found that probe BTREP15, from cattle, which shows $98 \%$ identity with probe Bt1, gave no signals when hybridized to chromosomes of Caprini tribes (genera Ovis, Capra and Ammotragus), in agreement with our results. However, the same authors detected hybridization signals when washing was done using lower stringency conditions (Kopecna et $a l ., 2012)$. The cause of the discrepancy may be related to different lineages used, each having distinct repetitive sequences. Moreover, differences in hybridization stringency and between probes may also be involved. Although belonging to the same family of satellite I DNA, different DNA sequences were employed in the various studies, thus implying that the 1.715 family of satellite I is composed of a number of subfamily sequences not necessarily identical to each other. In particular, Bt1 probe used in the present work represents a shorter ( $344 \mathrm{bp}$ ) sequence that is included in the larger probes pBtKB5 (566 bp) and BTREP15 (581 bp) used in the above-mentioned studies. Kopecna et al. (2014) extended their analysis employing different satellite DNA clones isolated by laser microdissection of centromeric regions in 38 bovid species. In all species analyzed, the satellite I probe gave a strong signal on acrocentric autosomes and a much weaker, or no signal, on biarmed autosomes. Biarmed X chromosomes also showed no satellite I hybridization, while all acrocentric X chromosomes, with exception of those of Caprini, were positive (Kopecna et al., 2014).

DNA satellite I is located mainly at or near centromeres (D'Aiuto et al., 1997). As expected, sequences were detected on every acrocentric autosome. The lack of signal in the bi-armed chromosomes of Bubalus bubalis and Ovis orientalis musimon is probably due to the loss of heterochromatin following Robertsonian translocations, an event producing a change in the number of chromosomes but not chromosome arms (Robertson, 1916; reviewed in Robinson and Ropiquet, 2011). Our results agree with data produced by Chaves et al. (2000) and by Davila-Rodriguez et al. (2009), who found that the amount of constitutive heterochromatin is greater in all pericentromeric regions of 

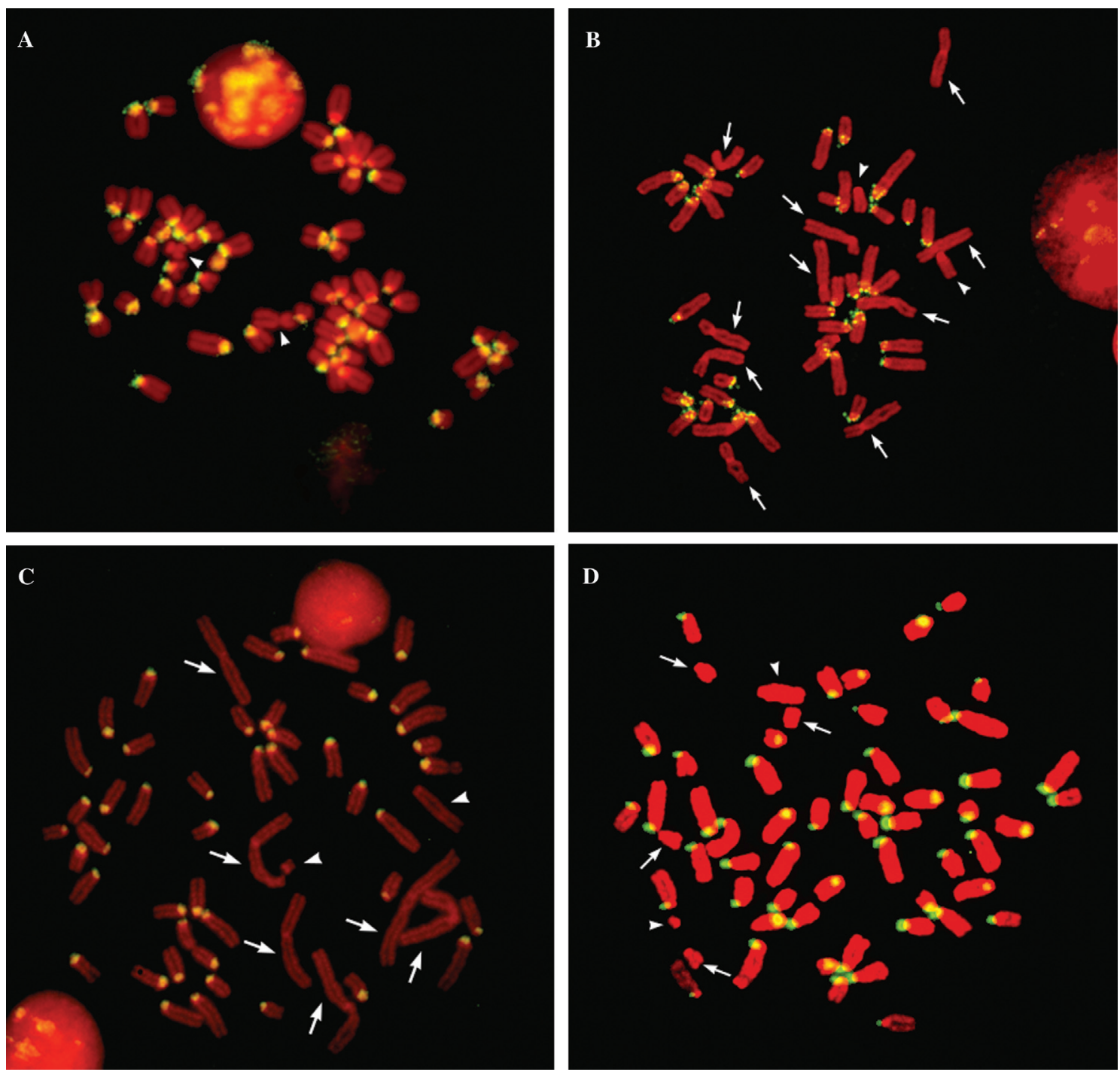

Figure 3 - Fluorescence in situ hybridization. A) Chromosomes from Bos taurus hybridized to probe Bt1. Signals are present in pericentromeric regions of every autosome, but not on the X and Y chromosomes (indicated by arrowheads). B) Chromosomes from Bubalus bubalis hybridized to probe Bt1. Signals are present in pericentromeric regions of acrocentric autosomes, but not on the five pairs of bi-armed autosomes (arrows), or on the X chromosomes (arrowheads). C) Chromosomes from Ovis orientalis musimon hybridized to probe Om1. Signals are detected on all acrocentric autosomes. No signal was detected on the three pairs of bi-armed autosomes (arrows), or on the $\mathrm{X}$ and $\mathrm{Y}$ chromosomes (arrowheads). D) Chromosomes from Capra hircus hybridized to probe Om1. Signals are detected on acrocentric autosomes, with the exception of two pairs of autosomes (arrows). No signal is visible on the $\mathrm{X}$ and Y chromosomes (arrowheads)

acrocentric chromosomes than in metacentric or sex chromosomes. However, the lack of signal on two pairs of autosomes in Capra hircus suggests, as an alternative interpretation, that the loss or rearrangement of heterochromatin precedes or is independent of chromosome fusions.

Moreover, finding the same hybridization pattern shared by Ovis orientalis musimon and Ovis aries, with a slightly different pattern observed in Capra hircus, is consistent with current phylogeny. The lack of signal on $\mathrm{X}$ and Y chromosomes, which has also been reported previously (Chaves et al., 2000, 2005), may have alternative explanations: either the absence of highly repetitive DNA in sex chromosomes, as suggested by Hornaday et al. (1994), or higher evolution rates of these sequences due to the lack of homologous recombination in the male sex. The latter interpretation is supported by the presence of satellite DNA (1.715 family) detected using probe BTREP15 on the Bubalus bubalis X chromosome, but absent in Bos taurus and Bison bonasus (Kopecna et al., 2012, 2014).

Finally, a totally unexpected finding was the nearly $100 \%$ homology between probe Om1 (1.714 family of satellite DNA) with a prokaryotic sequence present in Helicobacter pylori, a Gram-negative bacterium involved in the etiology of peptic ulcer. Lateral transfer of bacterial DNA into a mammalian genome has been previously suggested (Salzberg et al., 2001), but never proven. A more 
likely explanation is contamination from other species, which may masquerade as lateral gene transfer (Willerslev et al., 2002). A clear case of cross-species contamination, where Neisseria gonorrhoeae contained multiple sequences derived from cow and sheep genomes, has been recently reported (Merchant et al., 2014).

In conclusion, our results support the idea that rapidly-evolving satellite DNAs may be a useful tool in the still-controversial systematic studies of Bovidae. Being able to differentiate at a subfamily or tribal level, they will provide the additional information necessary to clarify the phylogeny of that family. However, results must be interpreted with great caution, since differences in satellite DNA may be quantitative (variation in copy number) or qualitative (variation in nucleotide sequence). Identical probes, as well as identical experimental conditions, must be employed for obtaining comparable data.

\section{Acknowledgments}

The authors are grateful to Mary Ann Groeneweg for revising the manuscript. This study was funded by Regione Autonoma della Sardegna: L.R. 7/2007.

\section{References}

Achilli A, Bonfiglio S, Olivieri A, Malusà A, Pala M, Kashani BH, Perego UA, Ajmone-Marsan P, Liotta L, Semino O, et al. (2009) The multifaceted origin of Taurine cattle reflected by the mitochondrial genome. PloS One 4:e5753.

Altschul SF, Madden TL, Schäffer AA, Zhang J, Zhang Z, Miller W and Lipman DJ (1997) Gapped BLAST and PSI-BLAST: a new generation of protein database search programs. Nucleic Acids Res 25:3389-3402.

Carcangiu V, Mura MC, Pazzola M, Vacca GM, Paludo M, Marchi B, Daga C, Bua S and Luridiana S (2011) Characterization of the Mediterranean Italian buffalo melatonin receptor 1A (MTNR1A) gene and its association with reproductive seasonality. Theriogenology 76:419-426.

Cau A, Coluccia E, Deiana AM, Pichiri G, Rossino R, Salvadori S and Mezzanotte R (1992) Chromosomes and DNA of Anguilla anguilla: a study with restriction endonucleases. Genome 35:838-843.

Chaves R, Guedes-Pinto H, Heslop-Harrison J and Schwarzacher $T$ (2000) The species and chromosomal distribution of the centromeric alpha-satellite I sequence from sheep in the tribe Caprini and other Bovidae. Cytogenet Cell Genet 91:62-66.

Chaves R, Guedes-Pinto H and Heslop-Harrison J (2005) Phylogenetic relationships and the primitive $\mathrm{X}$ chromosome inferred from chromosomal and satellite DNA analysis in Bovidae. Proc R Society Lond B 272:2009-2016.

Chessa B, Pereira F, Arnaud F, Amorim A, Goyache F, Mainland I, Kao RR, Pemberton JM, Beraldi D, Stear MJ, et al. (2009) Revealing the history of sheep domestication using retrovirus integrations. Science 324:532-536.

D'Aiuto L, Barsanti P, Mauro S, Cserpan I, Lanave C and Ciccarese S (1997) Physical relationship between satellite I and
II DNA in centromeric regions of sheep chromosomes. Chromosome Res 5:375-381.

Dávila-Rodríguez MI, Cortés-Gutiérrez EI, López-Fernández C, Pita M, Mezzanotte R and Gosálvez J (2009) Wholecomparative genomic hybridization in domestic sheep (Ovis aries) breeds. Cytogenet Genome Res 124:19-26.

Gallagher Jr DS, Davis SK, De Donato M, Burzlaff JD, Womack JE, Taylor JF and Kumamoto AT (1999) A molecular cytogenetic analysis of the tribe Bovini (Artiodactyla, Bovidae, Bovinae) with an emphasis on sex chromosome morphology and NOR distribution. Chromosome Res 7:481-492.

Gentry AW (1992) The subfamilies and tribes of the family Bovidae. Mam Rev 22:1-22.

Hornaday K, Alexander S and Breden F (1994) Absence of repetitive DNA sequences associated with sex chromosomes in natural populations of the Trinidad guppy (Poecilia reticulata). J Mol Evol 39:431-433.

Iannuzzi L, Di Meo GP and Perucatti A (1996) Identification of nucleolus organizer chromosomes and frequency of active NORs in river buffalo (Bubalus bubalis L.). Caryologia 49:27-34.

Kopecna O, Kubickova S, Cernohorska H, Cabelova K, Vahala J and Rubes J (2012) Isolation and comparison of tribespecific centromeric repeats within Bovidae. J Appl Genet 53:193-202.

Kopecna O, Kubickova S, Cernohorska H, Cabelova K, Vahala J, Martinkova N and Rubes J (2014) Tribe-specific satellite DNA in non-domestic Bovidae. Chromosome Res 22:277291. Erratum in: Chromosome Res 22:439-440.

Lei CZ, Zhang CM, Weining S, Campana MG, Bower MA, Zhang XM, Liu L, Lan XY and Chen H (2011) Genetic diversity of mitochondrial cytochrome $\mathrm{b}$ gene in Chinese native buffalo. Anim Genet 42:432-436.

Meadows JRS, Hiendleder S and Kijas JW (2011) Haplogroup relationships between domestic and wild sheep resolved using a mitogenome panel. Heredity 106:700-706.

Merchant S, Derrick DE and Salzberg SL (2014) Unexpected cross-species contamination in genome sequencing projects. Peer J 2:e675.

Moorhead PS, Nowell PC, Mellmann WJ, Battips DM and Hungerford DA (1960) Chromosome preparations of leukocytes cultured from human peripheral blood. Exp Cell Res 20:613-616.

Naderi S, Rezaei HR, Taberlet P, Zundel S, Rafat SA, Naghash HR, El-Barody MAA, Ertugru O and Pompanon F (2007) Large-scale DNA analysis of the domestic goat reveals six haplogroups with high diversity. PLoS One 10:e1012.

Nowak RM (1999) Walker's Mammals of the World. Vol. 2. The Johns Hopkins University Press, Baltimore.

Pita M, Gosálvez J, Gosálvez A, Nieddu M, López-Fernández C and Mezzanotte R (2009) A highly conserved pericentromeric domain in human and gorilla chromosomes. Cytogenet Genome Res 126:253-258.

Plohl M, Luchetti A, Mestrovic N and Mantovani B (2008) Satellite DNAs between selfishness and functionality: structure, genomics and evolution of tandem repeats in centromeric (hetero)chromatin. Gene 409:72-82.

Robertson WRB (1916) Chromosome studies. I. Taxonomic relationships shown in the chromosomes of Tettigidae and Acrididae: V-shaped chromosomes and their significance in 
Acrididae, Locustidae, and Gryllidae: Chromosomes and variation. J Morphol 27:179-331.

Robinson TJ and Ropiquet A (2011) Examination of hemiplasy, homoplasy and phylogenetic discordance in chromosomal evolution of the Bovidae. Syst Biol 60:439-450.

Salzberg SL, White O, Peterson J and Eisen JA (2001) Microbial genes in the human genome: Lateral transfer or gene loss? Science 292:1903-1906.

Vacca GM, Daga C, Pazzola M, Carcangiu V, Dettori ML and Cozzi MC (2010) D-loop sequence mitochondrial DNA variability of Sarda goat and other goat breeds and populations reared in the Mediterranean area. J Anim Breed Genet 127:352-360.
Vacca GM, Pazzola M, Pisano C, Carcangiu V, Diaz ML, Nieddu M, Robledo R, Mezzanotte R and Dettori ML (2011) Chromosomal localisation and genetic variation of the SLC11A1 gene in goats (Capra hircus). Vet J 190:60-65.

Willerslev E, Mourier T, Hansen AJ, Christensen B, Barnes I and Salzberg SL (2002) Contamination in the draft of the human genome masquerades as lateral gene transfer. DNA Seq 13:75-76.

Associate Editor: Marcelo Guerra

License information: This is an open-access article distributed under the terms of the Creative Commons Attribution License (type CC-BY), which permits unrestricted use, distribution and reproduction in any medium, provided the original article is properly cited. 